\title{
Detection of a Novel Mutation in the CACNA1A gene
}

\author{
Shani Stuart, Bishakha Roy, Gail Davies, Nevene Maksemous, Robert Smith and Lyn R. Griffiths \\ Genomics Research Centre, Griffith Health Institute, Griffith University, Brisbane, Australia
}

Familial hemiplegic migraine (FHM) is a rare autosomal dominant subtype of migraine with aura. It is divided into three subtypes FHM1, FHM2 and FHM3, which are caused by mutations in the CACNA1A, ATP1A2 and SCN1A genes respectively. As part of a regular diagnostic service, we investigated 168 patients with FHM symptoms. Samples were tested for mutations contained within the CACNA1A gene. Some tested samples (4.43\%) showed an FHM1 mutation, with five of the mutations found in exon 5, one mutation in exon 16 and one in exon 17. Four polymorphisms were also detected, one of which occurred in a large percentage of samples (14.88\%). The exon $162094 \mathrm{G}>\mathrm{A}$ polymorphism, however, has been found to occur in healthy Caucasian control populations up to a frequency of $16 \%$ and is not considered to be significantly associated with FHM. A finding of significance, found in a single patient, was the detection of a novel mutation in exon 5 that results in a $\mathrm{P} 225 \mathrm{H}$ change. The affected individual was an 8-year-old female. The exact phenotypic effect of this mutation is unknown, and further studies are needed to understand the pathophysiology of this mutation in FHM1. New information will allow for diagnostic procedures to be constantly updated, thus improving accuracy of diagnosis. It is possible that new information will also aid the development of new therapeutic agents for the treatment of FHM.

- Keywords: familial hemiplegic migraine, novel mutation, $\mathrm{P} / \mathrm{Q}$ calcium channel gene, hemiparesis, ion channel genes

Familial hemiplegic migraine (FHM; OMIM 141500) is a rare hereditary subtype of migraine with aura. It is typically accompanied by hemiparesis and a variety of neurological symptoms that may include both visual and motor sensory disturbances (Olesen, 2004; Ophoff, Terwindt, Frants, \& Ferrari, 1998). The prevalence of this disease has been estimated at around $0.01 \%$ in European populations, with familial FHM accounting for half the incidence rate. A sex ratio of three affected females to every one male has also been recorded, hence women are three times more likely to suffer from FHM than their male counterparts (Thomsen et al., 2002). FHM is autosomally dominantly inherited but shows variable expressivity and genetic heterogeneity with $70 \%$ to $90 \%$ penetrance (Rothner, 2001). In most cases, the phenotype is severe as a result of neural disturbances and, in rare cases, can be fatal after minor head traumas (Curtain, Smith, Ovcaric, M, \& Griffiths, 2006; Kors et al., 2001). Due to the strong genetic component of FHM, it has become a favorable target for the study of genes involved in migraine pathogenesis (Colson, Fernandez, Lea, \& Griffiths, 2007).
Three main genes have been implicated in the pathogenesis of FHM, namely CACNA1A (P/Q calcium channel), ATP1A2 (P-type $\mathrm{Na}^{+} / \mathrm{K}^{+}$ATPase), and SCN1A $\left(\mathrm{Na}^{+}\right.$channel $\alpha$ subunit), with a possibility of a fourth locus at 14q32 (Cuenca-León et al., 2008). This paper highlights the discovery of a novel mutation and the detection of a number of variants in the CACNA1A gene. Mutations in the calcium channel gene, CACNA1A, located on chromosome 19p13 have been linked to FHM1 in a number of family studies (Ophoff et al., 1996). Currently, 21 different missense mutations that cause FHM1 have been identified in the CACNA1A gene (de Vries, Frants, Ferrari, \& van den Maagdenberg, 2009). It is estimated that CACNA1A mutations account for $50 \%$ of

\footnotetext{
RECEIVED 27 June, 2011; ACCEPTED 7 October, 2011.
}

ADDRESS FOR CORRESPONDENCE: Lyn R. Griffiths, Genomics Research Centre, Griffith Health Institute, Building G05, Gold Coast Campus, Griffith University, Gold Coast QLD 4222, Australia.Email: l.griffiths@griffith.edu.au. 
FHM patients, and that it is this gene that is responsible for the majority of FHM cases (Wieser, 2003). CACNA1A encodes for the alpha $1 \mathrm{~A}$ subunit of the neuronal voltagedependant P/Q-type calcium channel.

Ion channel genes play a critical role in normal functioning of the central nervous system and neuromuscular pathways. Functional studies have shown that FHM mutations can lead to both gain and loss of function of P/Q-type calcium channels, all of which affect the physiological functioning of the channels in a variety of ways (Hans et al., 1999). Electrophysiological studies have shown that either an increased or decreased influx of $\mathrm{Ca}^{2+}$ ions into cells caused by mutations in the CACNA1A gene has an effect on the depolarized state of cells (Wieser, 2003). It has been shown that FHM1 mutations can produce gain-of-function $\mathrm{Ca}(\mathrm{v}) 2.1$ channels and, as a result, initiate cortical spreading depression, which is the phenomenon thought to underlie migraine aura. The increased activity of the $\mathrm{Ca}(\mathrm{v}) 2.1$ channel facilitates increased $\mathrm{Ca}(\mathrm{v}) 2.1$-dependant neurotransmitter release from cortical neurons, in particular, glutamate (D'Onofrio et al., 2009). A large amount of phenotypic heterogeneity of clinical symptoms is still observed, which is indicative of the complexity and variability of FHM1 (Wieser, 2003).

Current diagnostic protocol for FHM involves analysis of patient information by a clinician, according to criteria specified by the Headache Classification Subcommittee of the International Headache Society (Olesen, 2004). Suspected cases are then referred for molecular diagnosis by mutation analysis. Treatments such as administration of Triptans or $\beta$-blockers are commonly used approaches to treat common migraine and can also be used to treat FHM sufferers, but have limited success, depending on the individual (Arttoa, 2007; Ferrari, 2001). Other drugs used to treat hemiplegic migraines include verapamil, acetazolamide, ibuprofen, and calcium channel blockers. Most of these treatments were originally designed to target different disorders such as epilepsy, high blood pressure, cardiac arrhythmia, and glaucoma. Any medications that constrict arteries need to be avoided because this increases the risk of stroke. FHM and migraine with aura sufferers are already at an elevated risk for stroke, and drugs targeting high blood pressure can aggravate this predisposition (Diener \& Kurth, 2011). For the most part, treatments are still predominantly focused on alleviating symptoms, and the development of new therapeutics targeting specific pathways, especially those involving FHM, are needed.

\section{Materials and Methods}

\section{Patients}

Since beginning diagnostic processing in 1999, the Genomics Research Clinic at Griffith University (Gold Coast campus) has tested 587 patients for FHM, cerebral autosomal dominant arteriopathy with subcortical infarcts and leukoencephalopathy (CADASIL), and episodic ataxia type II (EA2)-causative mutations. DNA testing was undertaken at the request of clinical neurologists around Australia. These neurologists requested testing for FHM1 because, in each case, they had patients with symptoms suggestive of FHM. The DNA testing was requested to help to confirm or aid in a diagnosis. Clinical notes indicated that 25 patients, or $14.9 \%$ of patients, had a family history of FHM-related symptoms in other family members. For the other cases, no familial FHM references were recorded. Medical histories were noted in each case and are summarized in Table 1 . Of the 587 patients, 168 were tested for FHM1, FHM2, FHM3, or a combination thereof. Because the majority (50\%) of all known FHM causative mutations are harbored in the CACNA1A gene, this is the first test done and, therefore, all 168 patient samples underwent CACNA1A mutation testing. All mutations were noted and polymorphisms were recorded.

\section{Molecular Analysis}

A blood sample was taken from each patient, and whole DNA was extracted using a standard salting out procedure. DNA was then quantified and normalized to a concentration of $20 \mathrm{ng} / \mu \mathrm{l}$. Exons 4,5,16,17, and 36 of CACNA1A were amplified using AmpliTaq Gold DNA polymerase (Applied Biosystems). Standard National Association of Testing Authorities protocol for FHM1 testing was followed, including the use of recommended primers and thermocycling conditions. The forward and reverse primers for exon 5 in which the novel mutation was found are as follows: forward 5'CTTGGTGGCGGGGTTT3' and reverse 5'CTGCCTAATCCTCCCAAGAG3'. Following amplification, post polymerase chain reaction products were run on an agarose gel to check for sufficient amplification and DNA quality. Then an ExoSap cleanup step was done, before big dye termination sequencing on an ABI 3130 Genetic Analyser. Both the sense and antisense strands were sequenced. Chromas was used to view and interpret sequencing results. All polymorphisms and mutations were reported.

\section{Results}

Of a total 168 patient samples tested for FHM1, 7 (4.43\%) tested positive for a single mutation in the CACNA1A gene. Five of the mutations were found in exon 5, one mutation in exon 16, and one in exon 17. The serine to leucine mutation (Ser218Leu) occurred most frequently, accounting for $57 \%$ of the positive results. Each of the other mutations was found only once in the patient cohort. One of these mutations, (Pro225His), has never been reported previously. Table 1 summarizes the details and frequency of each mutation found. In addition, four polymorphisms were noted in other samples. The most frequently occurring polymorphism that was found is situated in exon 16 (rs 16016) and was detected in $14.88 \%$ of 
the patient samples. The other polymorphisms were found only in single patients, except for rs17846942, which was detected in two sisters. All polymorphisms that were detected are heterozygous and nonsynonomous. They are summarized in Table 2.

\section{Positive Mutation Results}

The Pro225His mutation was identified in an 8-year-old female patient. The patient was born prematurely (29 weeks gestation), presented with developmental delay, speech and spacial sense impairment, poor concentration, and epilepsy. Prior to the FHM test, no formal diagnosis had been made. However, in addition to these symptoms, the patient had at least four seizures that started with a headache and progressed to right-side twitching and then a generalized clonic seizure. This is the first report of this mutation in a patient with FHM symptoms. There was also a strong family history of a similar syndrome. The patient's mother has epilepsy and learning difficulties and has been diagnosed with FHM1. She suffered a stroke at age 11 years. The patient's grandmother had seizures as a neonate, and the patient's brother had epilepsy as a child.

\section{Discussion}

Our studies investigating 168 patients with potential FHM symptoms have identified six previously reported amino acid-changing mutations in the CACNA1A gene, and a novel mutation in an 8-year-old female patient. This is the first report of this mutation in a patient with FHM symptoms. It is unknown at what frequency this novel Pro225His mutation occurs in patients or in the population. To date, 21 known causative missense mutations are associated with FHM1 (de Vries et al., 2009). The most prevalent of these is a threonine to methione substitution at amino acid position 666 in exon 16 (Barrett, Cao, \& Tsien, 2005), which has been reported in many previous FHM studies (Ducros et al., 1999; Ophoff et al., 1996). This mutation was detected only once in our patient cohort. Other frequently reported mutations include Arg192G, Ser218Leu, and Arg583Gln (Chan et al., 2008; Ducros et al., 1999; Ducros et al., 2001; Kors et al.,
2001; Ophoff et al., 1998). The Ser218Leu mutation was the one found most frequently in our patient cohort and accounted for $57 \%$ of positive results. This mutation was originally reported by Curtain, et al. (2006) as part of previous investigative work in our patient cohort. The remaining previously reported mutation that we found was the Val714Ala change. This mutation has been published in at least two previous FHM studies (Ophoff et al., 1996; 1998).

Proline is a nonpolar, slightly alkaline amino acid with an aliphatic side chain. The cyclic structure of Proline gives its backbone dihedral angle an approximately $-75^{\circ}$ angle, which results in an exceptional conformational rigidity, compared to other amino acids. Proline acts as a structural disruptor in the middle of regular secondary structure elements such as alpha helices and beta sheets, and is commonly found in turns (Osvath \& Gruebele, 2003). Histidine is a polar, strongly alkaline amino acid with an aromatic imidazole ring (Kopple \& Swendseid, 1975). These two amino acids have drastically different chemical properties, thus a proline to histidine change in a tertiary protein structure could potentially disrupt protein function, depending on the domain in which the substitution occurs. The novel mutation detected in our 8-year-old patient occurs at amino acid position 225 of the CACNA1A protein. This change is positioned in a highly conserved intracellular loop of the alpha-1A subunit that can be viewed in the Swiss-Model Repository (Kiefer, Arnold, Künzli, Bordoli, \& Schwede, 2009; Kopp \& Schwede, 2004). The well-known S218L mutation occurring in the same protein domain has been reported in two patients from a family with extreme FHM, and in 1 patient whose parent had FHM and whose family suffered from various neurologic abnormalities (Kors et al., 2001). The replacement of a hydrophilic serine for a hydrophobic leucine at residue 218 in the highly conserved intracellular loop was suggested by the authors as a pathogenic change causing ionic perturbation, as a result of inappropriately depolarized ion channels. Even though the novel mutation identified occurs in a highly conserved domain of the CACNA1A protein, functional studies will need to be conducted to confirm if the

TABLE 1

Summary of Patient Information

\begin{tabular}{|c|c|c|c|c|}
\hline Diagnostic Patients & Age & Reported family history & Reported Symptom & \\
\hline \multirow[t]{7}{*}{168} & Range & $25(14.9 \%)$ & Periodic ataxia & $15(8.9 \%)$ \\
\hline & 91years-1year old & & Hemiplegia & $37(22.0 \%)$ \\
\hline & Median 40years & & Migraine & $56(33.3 \%)$ \\
\hline & & & $\begin{array}{l}\text { Concussion/loss of } \\
\text { consciousness/coma }\end{array}$ & $9(5.4 \%)$ \\
\hline & & & Stroke & $4(2.4 \%)$ \\
\hline & & & Paroxysmal vertigo & $4(2.4 \%)$ \\
\hline & & & Seizures/epilepsy & $9(5.4 \%)$ \\
\hline
\end{tabular}


amino acid change is pathogenic. A recent study found a surprisingly high level of missense single-nucleotide polymorphisms (SNPs) in ion channel genes in both affected patients and healthy controls, and it is possible that this may be a different mutation accounting for the disease phenotype of the patient (Klassen et al., 2011).

A number of common polymorphisms are also known to occur in the CACNA1A gene. The known nonpathogenic polymorphisms are summarized in Table 2 . The most frequent polymorphism found in our patient cohort is rs16016, which is estimated to occur in frequencies from $12 \%$ to $16 \%$ in Caucasian populations (NCBI, 2011). This polymorphism was found in almost $15 \%$ of our patient samples, but given how common rs16016 is in the European population, it unlikely to have any association with FHM, EA2, or spinocerebellar ataxia type 6 (SCA6). Similar frequencies of rs16016 were found in previous FHM studies, and this particular SNP has been reported as being non pathogenic (Ducros et al., 1999; Ophoff et al., 1996). Three other polymorphisms were found in our patient cohort, as illustrated in Table 1. Each polymorphism was detected in only one patient, except for rs17846942, which was found in two sisters. rs41276894 has a reported minor allele frequency of $0.6 \%$ in the Caucasian population and is considered to be a rare variant (NCBI, 2011). It has been reported to occur in frequencies of up to $2 \%$ in previous studies, and is also considered to be nonpathogenic (Ducros et al., 2001; Ophoff et al., 1996). There is very little published information available for the third polymorphism (5404-14C >T) that was detected in our patient cohort. It has been reported in the CACNA1A gene variation database, but it is unknown at what frequency the detected polymorphism occurs or what effect is has on protein function. Similarly, little information is available about rs17846942. It has a reported minor allele frequency of $6.3 \%$ in the Chinese

\section{TABLE 2}

Summary of Identified Mutations and Polymorphisms in our Patient Cohort

\begin{tabular}{|c|c|c|c|c|}
\hline \multicolumn{5}{|c|}{ Mutations } \\
\hline No. & Exon & Nucleotide change & Amino acid change & No. positive samples \\
\hline 1 & 5 & $653 \mathrm{C}>\mathrm{T}$ & Ser218Leu & 4 \\
\hline 2 & 5 & $674 C>A$ & Pro225His & 1 \\
\hline 4 & 16 & $1997 \mathrm{C}>\mathrm{T}$ & Thr666Met & 1 \\
\hline 5 & 17 & $2141 \mathrm{~T}>\mathrm{C}$ & Val714Ala & 1 \\
\hline \multicolumn{5}{|c|}{ Polymorphisms } \\
\hline No. & Exon/Intron & Nucleotide change & rs number & No. positive samples \\
\hline 1 & Exon 16 & $2094 \mathrm{G}>\mathrm{A}$ & rs 16016 & 25 \\
\hline 2 & Exon 36 & $5404-14 C>T$ & - & 1 \\
\hline 3 & Exon 4 & $579 \mathrm{G}>\mathrm{A}$ & rs41276894 & 1 \\
\hline 4 & Intron 3 & $540-30 C>G$ & rs17846942 & 2 \\
\hline
\end{tabular}

\section{TABLE 3}

Summary of Known Nonpathogenic Polymorphisms in CACNA1A

\begin{tabular}{|c|c|c|c|c|c|}
\hline Exon & DNA change & Amino acid change & Frequency (\%) & rs number & Study in which first reported \\
\hline 1 & c.1-53_1-54insGGC & No & 0.04 & - & Battistini et al. (1999) \\
\hline 4 & c. $579 \mathrm{G}>\mathrm{A}$ & No & 0.02 & $\begin{array}{c}\text { rs41276894 } \\
\text { Ophoff et al. (1996) }\end{array}$ & Ducros et al. (2001); \\
\hline 6 & $c .876 A>G$ & No & 0.07 & $\begin{array}{c}\text { rs16006 } \\
\text { Ophoff et al. (1996) }\end{array}$ & Ducros, Joutel, et al. (1999); \\
\hline 9 & c. $1199-31 A>G$ & No & 0.6 & rs16008 & Carrera et al. (1999) \\
\hline 11 & c. $1360 \mathrm{G}>\mathrm{A}$ & No & 0.02 & $\begin{array}{c}\text { rs41276886 } \\
\text { Ophoff et al. (1996) }\end{array}$ & Cricchi et al. (2007); \\
\hline 16 & c. $2094 \mathrm{G}>\mathrm{A}$ & No & 0.12 & $\begin{array}{c}\text { rs16016 } \\
\text { Ophoff et al. (1996) }\end{array}$ & Ducros, Joutel, et al. (1999); \\
\hline 19 & c. $2978 \mathrm{~A}>\mathrm{T}$ & No & 0.62 & rs16023 & Carrera et al. (1999) \\
\hline 19 & c. $3060 \mathrm{G}>\mathrm{A}$ & No & 0.62 & rs16025 & Carrera et al. (1999) \\
\hline 20 & c. $3313 \mathrm{G}>\mathrm{A}$ & No & 0.25 & rs16027 & Ducros, Joutel, et al. (1999) \\
\hline 20 & c. $3549 \mathrm{C}>\mathrm{T}$ & No & 0.02 & rs16029 & Carrera et al. (1999) \\
\hline 39 & c. $5742 C>T$ & No & 0.006 & rs16044 & Carrera et al. (1999) \\
\hline
\end{tabular}

Note: adapted from http://grenada.lumc.nl/LOVD2/FHM/variants.php?select_db=CACNA1A\&action=search_unique\&search_pathogenic_=-(CACNA1A variation database) 
and Japanese population and thus is considered a common polymorphism (NCBI, 2011). Because it is so common, it is extremely unlikely that it has a pathogenic effect. Other common previously detected polymorphisms are listed in Table 2. Of note are two polymorphisms that are particularly common in the Italian population (rs16023 and rs16025) and occur in frequencies of up to 62\% (Carrera, Stenirri, Ferrari, \& Battistini, 2001).

While FHM is inherited in a dominant Mendelian fashion, common migraine is a complex polygenic disease. As with other complex diseases, it is hypothesized that many small genetic variants interacting with the environment have an additive effect to bring about the condition (Maher \& Griffiths, 2011). It is unknown exactly which commonly occurring polymorphisms, or combination thereof, have an underlying effect on migraine pathogenesis, and it is therefore important to analyze all variants occurring in potential candidate genes and/or pathways. Even seemingly nonpathogenic polymorphisms should not be overlooked. A study by D'Onofrio et al. (2009) found that the interplay of two SNPs may have an influence on the P/Q-type channel function in several subtypes of migraine, although they do not play a role in FHM. Only when data from patients suffering from migraine with aura and migraine without aura were pooled were results found to be significant. This suggests that there is some overlap between different migraine subtypes.The general pathways in which the FHM genes are involved remain good candidates for studies trying to elucidate the pathophysiology of common migraine, and should be examined in detail.

\section{Conclusion}

This study reports the detection of a novel mutation in the CACNA1A gene. Because not all of the causative genes for FHM or for common migraine are known, it is essential to continue investigating novel mutations and variants. New information will allow for the production of more accurate diagnostic procedures and also aid the development of new therapeutic agents for the treatment of FHM (Fernandez, Colson, \& Griffiths, 2007). The general pathways in which the FHM genes are involved may also be good candidates for studies trying to elucidate the pathophysiology of common migraines (Maher \& Griffiths, 2011). Therefore, further research into FHM could also aid in better therapeutics for the treatment of common migraine.

\section{References}

Arttoa, V. (2007). Treatment of hemiplegic migraine with triptans. European Journal of Neurology, 14, 1053-1056.

Barrett, C. F., Cao, Y. Q., \& Tsien, R. W. (2005). Gating deficiency in a familial hemiplegic migraine type 1 mutant $\mathrm{P} / \mathrm{Q}$-type calcium channel. Journal of Biological Chemistry, 280, 24064-24071.
Battistini, S. S. S., Piatti, M., Gelfi, C., Righetti, P. G., Rocchi, R., Giannini, F., Battistini, N., Guazzi, G. C., Ferrari, M., \& Carrera, P. (1999). A new CACNA1A gene mutation in acetazolamide-responsive familial hemiplegic migraine and ataxia. Neurology, 53, 38-43.

Carrera, P. P. M., Stenirri, S., Grimaldi, L. M., Marchioni, E., Curcio, M., Righetti, P. G., Ferrari, M., Gelfi, C. (1999). Genetic heterogeneity in Italian families with familial hemiplegic migraine. Neurology, 53, 26-33.

Carrera, P., Stenirri, S., Ferrari, M., \& Battistini, S. (2001). Familial hemiplegic migraine: An ion channel disorder. Brain Research Bulletin, 56, 239-241.

Chan, Y. C., Burgunder, J.-M., Wilder-Smith, E., Chew, S.E., Lam-Mok-Sing, K. M. J., Sharma, V., \& Ong, B. K. (2008). Electroencephalographic changes and seizures in familial hemiplegic migraine patients with the CACNA1A gene S218L mutation. Journal of Clinical Neuroscience, 15, 891-894.

Colson, N., Fernandez, F., Lea, R., \& Griffiths, L. (2007). The search for migraine genes: An overview of current knowledge. Cellular and Molecular Life Sciences, 64, 331-344.

Cricchi, F. D. L. C., Grieco, G. S., Rengo, C., Cardinale, A., Racaniello, M., Santorelli, F. M., Nappi, G., Pierelli, F., \& Casali, C. (2007). Early-onset progressive ataxia associated with the first CACNA1A mutation identified within the III loop. Journal of Neurological Sciences, 254, 67-71.

Cuenca-León, E., Corominas, R., Fernàndez-Castillo, N., Volpini, V., del Toro, M., Roig, M., Macaya, A., \& Cormand, B. (2008). Genetic analysis of 27 Spanish patients with hemiplegic migraine, basilar-type migraine and childhood periodic syndromes. Cephalalgia, 28, 1039-1047.

Curtain, R. P., Smith, R. L., Ovcaric, M., \& Griffiths, L. R. (2006). Minor head trauma-induced sporadic hemiplegic migraine coma. Pediatric Neurology, 34, 329-332.

D’Onofrio, M., Ambrosini, A., Di Mambro, A., Arisi, I., Santorelli, F. M., Grieco, G. S., Nicoletti, F., Nappi, G., Pierelli, F., Schoenen, J., \& Buzzi, M. G. (2009). The interplay of two single nucleotide polymorphisms in the CACNA1A gene may contribute to migraine susceptibility. Neuroscience Letters, 453, 12-15.

de Vries, B., Frants, R., Ferrari, M., \& van den Maagdenberg, A. (2009). Molecular genetics of migraine. Human Genetics, 126, 115-132.

Diener, H. C., \& Kurth, T. (2011). Migraine and stroke (5th ed.) (pp. 720-733). Saint Louis: W.B. Saunders.

Ducros, A., Denier, C., Joutel, A., Cecillon, M., Lescoat, C., Vahedi, K., Darcel, F., Vicaut, E., Bousser, M. G., \& Tournier-Lasserve, E. (2001). The clinical spectrum of familial hemiplegic migraine associated with mutations in a neuronal calcium channel. The New England Journal of Medicine, 345, 17-25.

Ducros, A. D. C., Joutel, A., Vahedi, K., Michel, A., Darcel, F., Madigand, M., Guerouaou, D., Tison, F., Julien, J., Hirsch, E., Chedru, F., Bisgård, C., Lucotte, G., Després, P., Billard, C., Barthez, M. A., Ponsot, G., Bousser, M. G., \& TournierLasserve, E. (1999). Recurrence of the T666M calcium channel CACNA1A gene mutation in familial hemiplegic 
migraine with progressive cerebellar ataxia. American Journal of Human Genetics, 68, 89-98.

Fernandez, F., Colson, N. J., \& Griffiths, L. R. (2007). Pharmacogenetics of migraine: Genetic variants and their potential role in migraine therapy. Pharmacogenomics, 8, 609.

Ferrari, M. D. (2001). Meta-analysis of rizatriptan efficacy in randomized controlled clinical trials. Cephalalgia, 21, 129-136.

Hans, M., Luvisetto, S., Williams, M. E., Spagnolo, M., Urrutia, A., Tottene, A., Brust, P. F., Johnson, E. C., Harpold, M. M., Stauderman, K. A., \& Pietrobon, D. (1999). Functional consequences of mutations in the human alpha $1 \mathrm{~A}$ calcium channel subunit linked to familial hemiplegic migraine. Journal of Neuroscience, 19, 1610-1619.

Kiefer, F., Arnold, K., Künzli, M., Bordoli, L., \& Schwede, T. (2009). The SWISS-MODEL Repository and associated resources. Nucleic Acids Research, 37, D387-D392.

Klassen, T., Davis, C., Goldman, A., Burgess, D., Chen, T., Wheeler, D., McPherson, J., Bourquin, T., Lewis, L., Villasana, D., Morgan, M., Muzny, D., Gibbs, R., \& Noebels, J. (2011). Exome sequencing of ion channel genes reveals complex profiles confounding personal risk assessment in epilepsy. Cell, 145, 1036-1048.

Kopp, J., \& Schwede, T. (2004). The SWISS-MODEL Repository of annotated three-dimensional protein structure homology models. Nucleic Acids Research, 32, D230-D234.

Kopple, J. D., \& Swendseid, M. E. (1975). Evidence that histidine is an essential amino acid in normal and chronically uremic man. The Journal of Clinical Investigation, 55, 881-891.

Kors, E. E., Terwindt, G. M., Vermeulen, F. L., Fitzsimons, R. B., Jardine, P. E., Heywood, P., Love, S., van den Maagdenberg, A. M., Haan, J., Frants, R. R., \& Ferrari, M. D. (2001). Delayed cerebral edema and fatal coma after minor head trauma: Role of the CACNA1A calcium channel subunit gene and relationship with familial hemiplegic migraine. Annals of Neurology, 49, 753-760.

Maher, B., \& Griffiths, L. (2011). Identification of molecular genetic factors that influence migraine. Molecular Genetics and Genomics, 285, 433-446.

NCBI. (2011). rs41276894. Retrieved from http://www. ncbi.nlm.nih.gov/snp?term $=$ rs41276894

Olesen, J. (2004). Preface to the Second Edition. Cephalalgia, 24, 9-10.

Ophoff, R. A., Terwindt, G. M., Frants, R. R., \& Ferrari, M. D. (1998). P/Q-type $\mathrm{Ca}^{2+}$ channel defects in migraine, ataxia and epilepsy. Trends in Pharmacological Sciences, 19, 121-127.

Ophoff, R. A., Terwindt, G. M., Vergouwe, M. N., van Eijk, R., Oefner, P. J., Hoffman, S. M. G., Lamerdin, J. E., Mohrenweiser, H. W., Bulman, D. E., Ferrari, M., Haan, J., Lindhout, D., van Ommen, G. J., Hofker, M. H., Ferrari, M. D., \& Frants, R. R. (1996). Familial hemiplegic migraine and episodic ataxia type- 2 are caused by mutations in the $\mathrm{Ca}^{2+}$ channel gene CACNL1A4. Cell, 87, 543-552.

Osvath, S., \& Gruebele, M. (2003). Proline can have opposite effects on fast and slow protein folding phases. Biophysical Journal, 85, 1215-1222.

Rothner, A. D. (2001). Complicated migraine and migraine variants. Seminars in Pediatric Neurology, 8, 7-12.

Thomsen, L. L., Eriksen, M. K., Romer, S. F., Andersen, I., Ostergaard, E., Keiding, N., Olesen, J., \& Russell, M. B. (2002). An epidemiological survey of hemiplegic migraine. Cephalalgia, 22, 361-375.

Wieser, T. (2003). Absence of known familial hemiplegic migraine (FHM) mutations in the CACNA1A gene in patients with common migraine: Implications for genetic testing. Clinical Chemistry and Laboratory Medicine, 41, 272-275. 